\title{
Current Situation and Countermeasures of Juvenile Cybercrime
}

\author{
Chen Xuanchi \\ People's Public Security University of China, Beijing, China \\ Keywords: teenagers; caber crime; current situation; Countermeasures \\ Abstract: At the fortieth anniversary of reform and opening-up, the socialist market \\ economy reform has entered a deep-water area. With the rapid development of economy \\ and society, the demand for material and cultural resources has been expanding, coupled \\ with the explosive growth of information brought by the rapid development of the \\ Internet, complex social life has brought psychological and material impacts on young \\ people who are far from mature. Under the new situation, juvenile delinquency has \\ entered an unprecedented stage. The total number of juvenile delinquency has been \\ rising, and the proportion of juvenile delinquency in the total number of criminal of \\ fences in China has remained high, which has attracted wide attention from all walks of \\ life. Therefore, this paper chooses domestic juvenile delinquency as the research object \\ under the new situation.
}

Juvenile delinquency, defined from the perspective of criminology, refers to the criminal acts committed by people aged 14-25, including illegal acts against social security and bad acts against moral norms. This definition expands the scope of criminal acts to illegal acts and bad acts, where bad acts refer to immoral acts or acts that may lead to crime. Therefore, it is pointed out that juvenile delinquency refers to social harmful acts committed by people aged 14-25. Generally speaking, juvenile delinquency includes a wider range of acts. From the perspective of professional research, the juvenile delinquency we refer to generally refers to criminal acts involving criminal law.

\section{Characteristics of Juvenile Cybercafe}

The so-called caber crime refers to the serious harm to society and even violation of specific criminal law committed by criminals on the network by exploiting the loopholes in their programming, encryption, decoding technology or tools, software instructions, product encryption technology and legal provisions, or by taking advantage of their special status as a network provider or other means. Like other social crimes, juvenile cybercafe has the basic characteristics of social harmfulness, illegal behavior and punishment by criminal law. However, as a new social crime phenomenon, especially in the high-tech field committed by the special group of juveniles, it has its own characteristics. Most of the teenagers who commit cybercafe have high educational background, can operate computer skillfully, and have strong skills in computer technology. Juvenile caber crime is a caber-induced crime. The good and meaningful information on the Internet 
has a negative impact on the values and outlook on life of teenagers, which is the basic cause of counterinsurgency.

Counterinsurgency has very high concealment. The otherworldly is a virtual space. The methods of cybercafe are mostly implemented through the operation of procedures and data. The invisibility of cybercafe makes it difficult to detect. Counterinsurgency has the character of "beyond time and space". The time required for the implementation of cybercafe is very short, which brings great difficulties to the investigation and evidence collection. On the other hand, the location of the crime is uncertain, which also makes the case detection impossible. Counterinsurgency is harmful to society and causes serious economic losses. Early hackers mostly destroyed other people's secret system to show their superb technology. Today, the goal of juvenile cybercafe is directly directed at computer information system which is related to national economy, people's livelihood and national security. Electronic money contains the great risk of triggering financial crisis, which is often attacked by hackers nowadays.

\section{Current situation of juvenile Cybercafe}

In recent years, the popularity of the Internet has increased rapidly, but the cases of juvenile cybercafe are also on the rise. According to the survey in Jungian, Shanghai and Shijiazhuang provinces, the proportion of juvenile cybercafe is increasing, which has a serious impact on society and economy. There are many kinds of juvenile cybercafe. It can be said that besides homicide and other crimes that directly infringe on the person, almost all other crimes can be carried out on the network, such as electronic theft, online fraud, online intimidation and so on. According to the information reported publicly by relevant departments, cybercafe in China is increasing year by year, while the age limit is declining, mostly for teenagers aged 16 to 17. Although the current juvenile cybercafe in China is not as prominent as that in the West, it is expected that in the next few years, such crimes will become one of the most harmful crimes in society. As shown in figure 1:

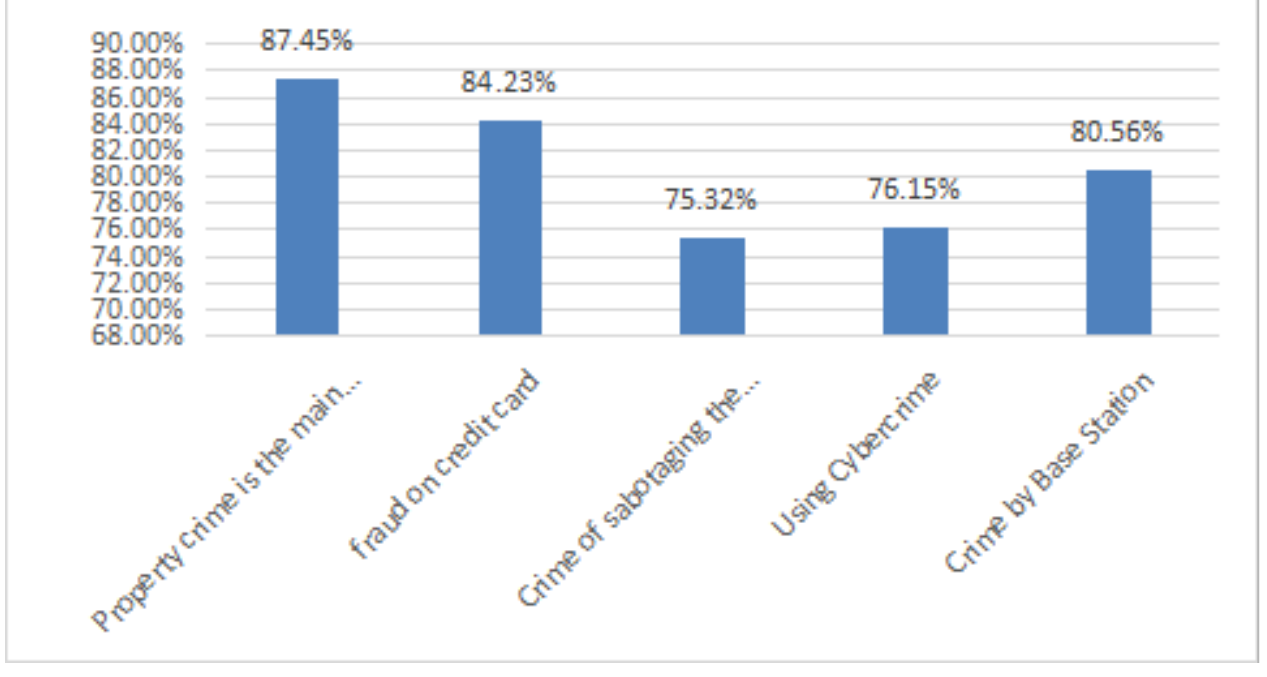

Figure 1. Performance of juvenile delinquency

\section{Measures to Reduce Juvenile Delinquency}

Under the current new situation, the countermeasures to reduce juvenile delinquency should include two aspects: prevention beforehand and treatment afterwards, prevention includes prevention beforehand and prevention of recidivism, and governance includes two aspects: prison 
education and execution education outside prison. Are-prevention can make juveniles at the edge of crime turn back in time, strengthen guidance can let them return to the right path; post-treatment can help juveniles to correct their mistakes, reform success can continue to serve the community, effectively reduce recidivism. As shown in Figure 2:

\section{Maintaining preadolescence and mental balance}

\section{Playing the Role of Family Education}

\section{Further strengthen school education}

\section{Strengthen juvenile legal system construction}

Figure 2. Measures to Reduce Juvenile Delinquency

\subsection{Maintaining preadolescence and mental balance}

With the improvement of economic level, the physical maturity of adolescents is generally earlier than before, which is the necessity of social development and can not be reversed. Therefore, we should start to improve the psychological maturity of adolescents, in order to maintain the balance of physical and mental development of adolescents. One is to establish single-parent family service stations, which can provide educational services and psychological counseling or counseling services for children of single-parent families in a way led by the government and organized by the public, so as to prevent the psychological imbalance of adolescents caused by family accidents.

The second is to establish youth volunteer service stations, vigorously promote youth participation in voluntary service activities, practice socialist core values with practical actions, and promote the spirit of "everyone for me, I for everyone"; the third is to carry out "social adaptation" training activities, which can be regularly set up by schools or social organizations, such as military training, summer camp, winter camp, expansion training. Fourthly, we should carry out typical education, combine with the characteristics of the times, strengthen the propaganda of typical characters, local history, good people and good deeds, and so on, to overcome cultural impetuosity and create a correct atmosphere of public opinion guidance for the society.

\subsection{Playing the Role of Family Education}

Family, as the cell of society, is the most important force affecting the lives of young people and the most effective medium of social control. Therefore, to curb juvenile delinquency, we should start with family. Family education is an important part of the whole education system and a basic form of education. As parents, bringing children into the world has the responsibility and obligation to cultivate and educate children. According to the traditional Chinese culture, "If you don't teach, your father's fault", parents naturally have the duty to educate their children, which can not be shirked. In a family environment, nontransparent standards and codes of conduct can imperceptibly affect children's growth in daily life. Harmonious family environment, parents who are good at education, can cultivate children with good quality, naturally can keep children away from bad moral behavior or even criminal behavior. 


\subsection{Further strengthen school education}

We will intensify educational reform, improve educational reform measures and further enhance the role of work-study schools. Although quality education has been carried out for a relatively long time in China, there are still many places, especially in remote areas, which have not been really implemented, and the popularity of quality education is not high. The current so-called exam-oriented education system, its drawbacks in recent years are very prominent. Only by breaking the current education system, can the school's education system be further reformed. In addition to considering the enrollment rate, the state should introduce appropriate measures to further promote the development of quality education, requiring schools and teachers to pay more attention to the healthy growth of adolescents.

Teachers of other disciplines should also receive regular legal education training to improve their legal awareness. Strengthen the responsibility of schools and teachers, do a good job of ideological transformation of students with poor moral performance, do not easily label students as "poor students", create unnecessary grade differences artificially, avoid intensifying contradictions and eliminate the hidden dangers of crime. In the current situation of extremely strong social competition consciousness, how to let students correctly deal with competition, how to correctly face the negative impact caused by competition, more reflected in the improvement of schoolteacher quality and the transformation of educational ideas.

\subsection{Strengthen juvenile legal system construction}

Juvenile legal system construction is an important part of the overall legal system construction of the country. The level of juvenile legal system development directly reflects the level of legal civilization development of a country or a region. Whether a society can effectively solve the problem of juvenile delinquency is also one of the indicators to measure the level of social development. Therefore, the construction of juvenile legal system with Chinese characteristics is an important and arduous task in the legal construction of our country, and also a social problem we are facing.

It is suggested that the concept of juvenile delinquency should be incorporated into the law as soon as possible so as to make the concept of juvenile delinquency have legal status. It is suggested that juveniles with bad behavior, or juveniles at the risk of crime, should be intervened by law, and the relevant matters of intervention should be included in the relevant laws for the prevention of juvenile delinquency, so that the prevention of juvenile delinquency can be effectively carried out in accordance with the law. We should improve the juvenile justice system, standardize juvenile courts, unify standards, and standardize juvenile curatorial procedures and trial methods. We suggest that the legislature formulate as soon as possible the juvenile probation regulations, the juvenile probation management and supervision system, and the juvenile rehabilitation laws and regulations.

\section{Conclusion}

The prevention and management of juvenile cybercafe is not only related to the legal protection of high-tech, but also to the healthy growth of the younger generation. In order to achieve better results, we should prevent and control such crimes from various angles of Criminology and sociology. On October 18, 2017, the 19th National Congress of the Communist Party of China was solemnly held in Beijing. General Secretary Xi Beijing clearly pointed out in the report of the Nineteenth National Congress: "Youth will prosper while youth will be strong. Youth generation will have ideals, abilities and responsibilities, the country will have a future, the nation will have hope, and the Chinese dream of great rejuvenation of the Chinese nation will eventually become a 
reality in the relay struggle of generations of youth." Therefore, in the new situation, exploring the causes of juvenile delinquency and putting forward corresponding prevention and treatment countermeasures are of great significance for promoting the healthy growth of juveniles and maintaining social harmony and stability, and eliminating resistance for the realization of the Chinese dream.

\section{References}

[1] Li Housemen, Sun Xiang. Current situation and Countermeasures of juvenile delinquency in China [J]. Shannon Police College Journal, 2000 (5).

[2] Sun Cedar, the current situation and characteristics of juvenile delinquency and typical case sources: China's juvenile rights protection Heart

[3] Jingo Duo, He Shana and Lou Dong. A review of the relationship between family factors and juvenile delinquency [J]. Advances in Science, 2006, 14 (3): 394-400.

[4] Kan Nashua. Definition and meaning of the concepts of juvenile delinquency and juvenile delinquency [J]. Shijiazhuang Police Science Journal of the College, 2000 (3): 15-19.

[5] Chen Homecoming. School and Juvenile Delinquency Prevention: Based on Social Control Theory [J]. Juvenile Delinquency Crime, 2004 (4): 4-10. 